\title{
Study on Tied Arch Bridge with Through Girder Design
}

\author{
Xun $\mathrm{Wu}^{1, \mathrm{a} *}$, Hui $\mathrm{Li}^{1, \mathrm{~b}}$, Zhichao Zhang ${ }^{1, \mathrm{c}}$ \\ ${ }^{1}$ Dept. of Bridge Engineering, Tongji University, Shanghai 200092, China \\ awuxun@tongji.edu.cn, blhlh6098358@163.com, 2013zhangzhichao@tongji.edu.cn \\ ${ }^{*}$ Corresponding author
}

Keywords:Tied Arch Bridge with Through Girder, Bridge Structure Design, Prestressed Concrete, Arch Section Change, Mechanical Performance

\begin{abstract}
Tied arch bridge with through girder mainly consists of girder, arch rib, suspender and prestressed steel bares for its superstructure. In terms of its overall mechanical performance, there are many factors affecting its mechanical performance.The factors are main girder section form, arrangement of prestressed reinforcement in the main girder, the arch rib section form and suspender stress.For the design of tied arch bridge with through girder,suspender spacing and girder cross section forms can be regarded as invariants according to the mechanical characteristics of arch bridge, the other influencing variables can be changed to research the performance of different components on the bridge.In the process of research, the structure performance must be always maintained coordination.
\end{abstract}

\section{Engineering Background}

The mainspan of Ningqi Railway is over 64 meters, and the line curve radius is 1600 meters. The clear height limitation of Hutong Railway causes that the building height of Ningqi Railway Bridge can not be more than 2.4 meters. So the low height structure schemes were researched in the selection of structure. A 64-meter simply supported tied arch bridge with through girder was recommended to cross Hutong Railway after months of research.

In the past, tied arch bridgeswith through girder were widely used and studied,while less work was done to research the mechanical performance of their composite structures, this paper tried to find some mechanics regularity.

\section{Study on Tied Arch Bridge with Through Girder Mechanics Regularity}

Tied arch bridge with through girder mainly consists of girder, arch rib, suspender and prestressed steel bares for its superstructure, In terms of its overall mechanical performance, there are many factors affecting its mechanical performance, they are main girder section form, arrangement of prestressed reinforcement in the main girder, the arch rib section form and suspender stress. With 64-meter Ningqi Railway Bridge as an example, in the case of ensuring the overall mechanical performance coordination, the control variable method was adopted respectively to study the influence factors on the resistance of bridge structure.

The Influence of Prestress on Tied Arch Bridge with Through Girder Resistance.Prestressed concrete has great help on the mechanical performance of concrete structure by promotion, under different prestressing force, each component oftied arch bridgewith through girder can exhibit different stress state.By changing the prestress, the influence on structure and each component can be seen.Under the condition of meeting all requirements of structural safety and force coordination, seven prestressed load cases were set up, for convenient modeling, decreasing prestress ways were equivalently used to reduce the number of prestressed steel bar.

The Influence of Different Prestress on Upper Flange Stress of Girder.As shown in Figure 1, when the prestresswas increased, the girder upper flange stress was increased, and the increase was considerable. 
The Influence of Different Prestress on Lower Flange Stress of Girder. As shown in Figure 2, when the prestresswas increased, the girder lower flange stress was increased, and the increase was considerable.
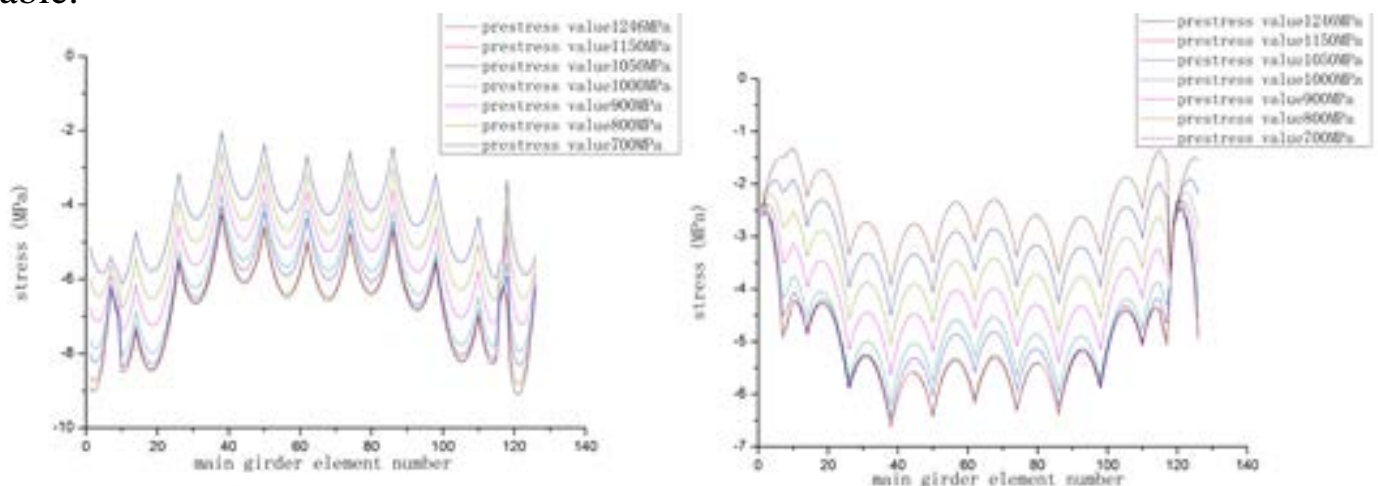

Figure 1. Different Prestress Influence Figure 2. Different Prestress Influence on Upper Flange Stress on Lower Flange Stress

The Influence of Different Prestress on Suspender Stress. As shown in Figure 3, when prestressedwas increased, the suspender stress almost did not change, the creep and shrinkage of girder and overall deformation coordination of bridge were the main cause of the above situation.

The Influence of Different Prestress on Vertical Displacement of Girder.As shown in Figure 4, when prestressedwas increased, the vertical displacement of the main girder was increased, this was due to that the neutral axis was above the centroid of prestressed girder structure. Although the increasing of prestresscouldincrease the vertical displacement of the main girder, the increasing value was very limited, in less than $5 \%$, so, the increasing of the prestress had little effect on the vertical displacement of the main girder.

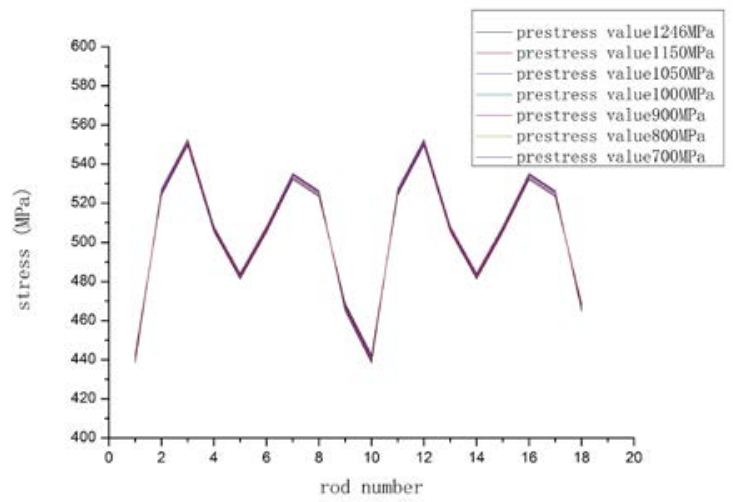

Figure 3. Different Prestress Influence on Suspender Stress

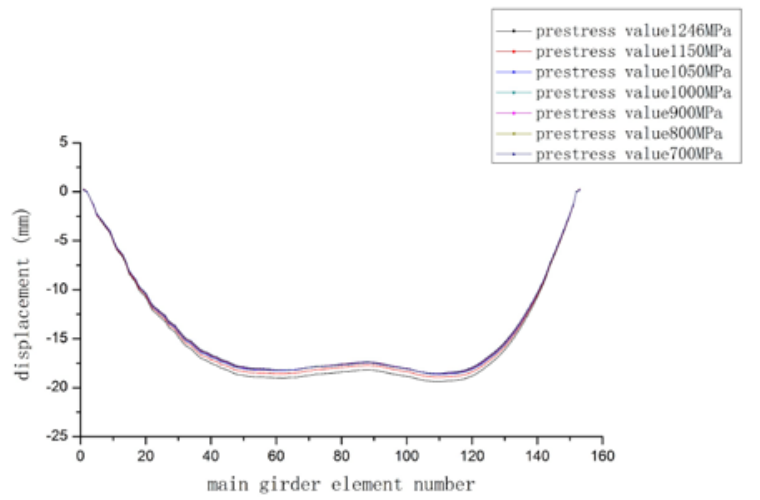

Figure 4. Different Prestress Influence on Girder Vertical Displacement

Summary. Prestress changes had large impact on the structural strength, the increasing of prestress could significantly increase the compressive stressand improve the flexural bearing capacity of cross section; prestress changeshad little effect on the stiffness of the structure. When the span of the structure becomes larger, it could meet the strength requirements by adjusting the prestress.

The Influence of Arch Rib Section Formon Tied Arch Bridge with Through Girder Resistance.The arch rib is an important component for tied arch bridge with through girder, the change of arch rib section form will have a direct influence on the rigidity of the arch. By changing the diameter and thickness of the arch rib section, the mechanical performance of bridge structure was researched.

The Influence of Different Arch Rib Section on Upper Flange Stress of Girder.As shown in Figure 5, when arch rib section diameter and thickness was increased, arch rib rigidity became larger, under the same suspender forces, upper flange stress was decreased. 
The Influence of Different Arch Rib Section on Lower Flange Stress of Girder.As shown in Figure 6, whenarch rib section diameter and thickness was increased, arch rib rigidity became larger, under the same suspender forces, upper flange stress was increased.

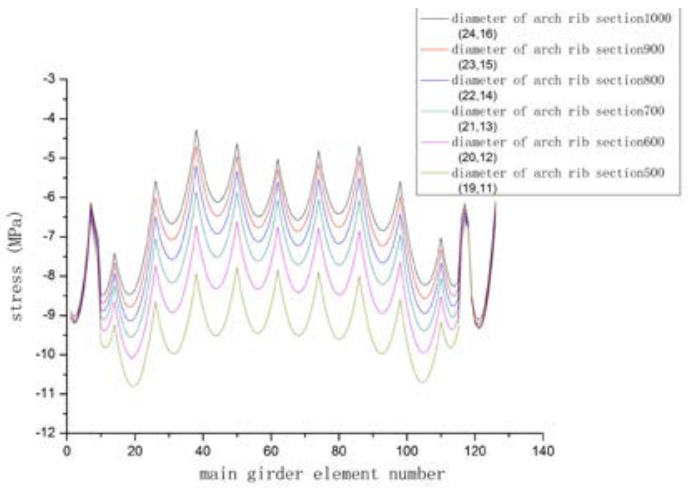

Figure 5. Different Arch Rib Section on Upper Flange Stress

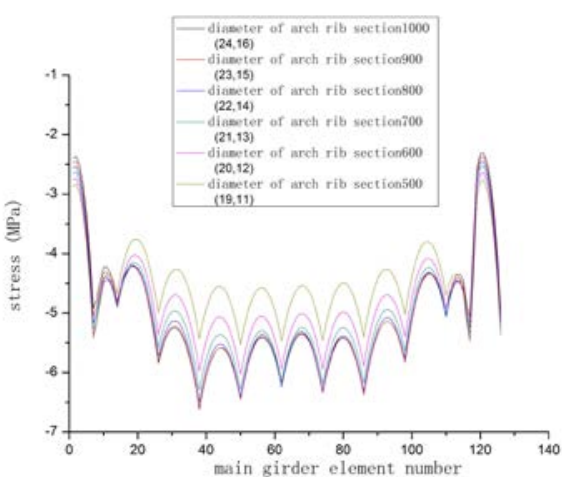

Figure 6. Different Arch Rib Section on Lower Flange Stress

The Influence of Different Arch Rib Section on Suspender Stress. As shown in Figure7, whenarch rib section diameter and thickness was increased, the suspender stress was decreased slightly, the influence was little in general.

The Influence of Different Arch Rib Section on Vertical Displacement of Girder. As shown in Figure 8, whenarch rib section diameter and thickness was increased, arch rib rigidity became larger, the vertical displacement of girder was significantly reduced, arch rib section diameter and thickness had an important influence on vertical displacement of girder.

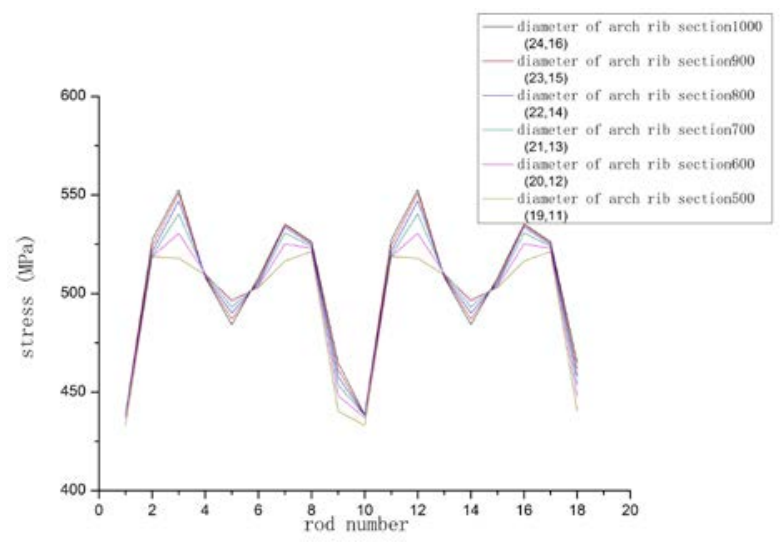

Figure 7. Different Arch Rib Section on Suspender Stress

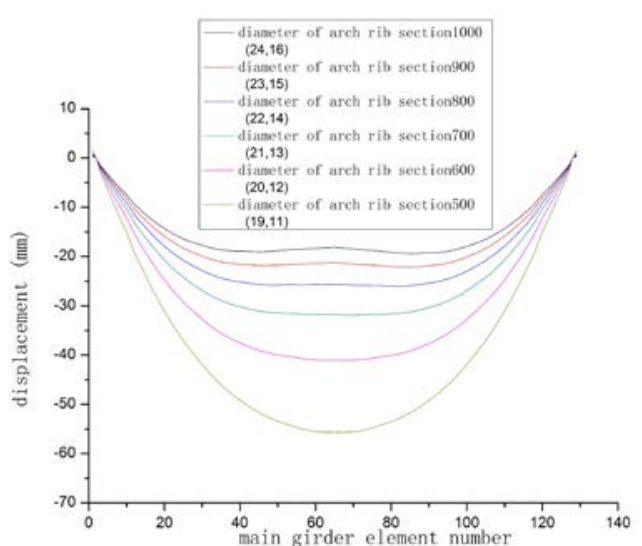

Figure 8. Different Arch Rib Section on GirderVertical Displacement

Summary.The change of the arch rib section has significant effect on stiffness of the structure, especially on the vertical displacement of girder structure under the action of live load. When the arch rib section diameter and the thickness were increased, the vertical displacement of girder under live and dead load was significantly decreased. Arch rib section change can also affect the girder cross section stress distribution. Under the same suspender force, when the arch rib section diameter and thickness were increased, upper flange stress of girder on the same cross section stress was decreased, and lower flange stress of girder was increased; the influence of arch rib section change on suspender stress is small. So, when the structure span becomes larger, the arch rib section can be changed to meet the stiffness requirement. At the same time, the change of arch rib section can also adjust the internal force distribution of the main girder to meet the strength requirements. 


\section{Conclusion}

1) According to the comparative study of the parameters of 64-meter tied arch bridge with through girder,with the same main girder cross section and suspender stress, the change of main girder prestress has significant influence on bridge structural strength, and the change of arch rib section effects the same cross section of girder stress distribution.

2) Arch rib section form and thickness hassignificant influence on the rigidity of structure, especially the girder deflection under live load effect, the change of the main girder prestress and suspender force effects little in the stiffness of the bridge.

3) In the construction phase, the prestress and the suspender force determines the stress and displacement state force of each construction stage. So, in order to meet the construction state requirements, the design of prestress and suspender force should be coordinated with the whole structure.

\section{References}

[1] Xun Wu, Peng Zhang: Urban Mass Transit Vol.10(2009), P. 73(In Chinese)

[2] DingwenWang ,Airong Liu et al: City Bridges and flood V03 (2004), P.37-40(In Chinese)

[3] Yingtao Sun, Huai Chen, Yaping Yang. World Bridges V01(2008), P.46-47 (In Chinese)

[4] Chuansu Wang: Research On Structural Static Behavior of Channel Girder\&Arch Composite Bridge in Rail Transit, Southwest Jiaotong University Master Dissertation(2009),P.4-6(In Chinese)

[5] Xun Wu,Dong Gu: Local Stress Analysis of Arch Foot for Through Girder and Arch Composite Bridge [A], Hangzhou Conference(2014),P.961-964(In Chinese)

[6] Xun Wu,Dong Gu: Mechanical Behavior Analysis of Through Girder and Arch Composite Bridge [A], Changsha Conference(2014),P.957-959 (In Chinese) 